\title{
Multi-Criteria Decision-Making Model Evaluating the Performance of Vietnamese Commercial Banks
}

\author{
Dinh Xuan Cuong ${ }^{1}$, Hoang Thi Hien ${ }^{1} \&$ Tran Long ${ }^{1}$ \\ ${ }^{1}$ Faculty of Finance and Banking, University of Economics and Business - Vietnam National University, Hanoi, \\ Vietnam \\ Corresponding: Dr. Dinh Xuan Cuong, Visiting Professor, Faculty of Finance and Banking, University of Economics \\ and Business - Vietnam National University, 144 Xuan Thuy Street, Hanoi, Vietnam.
}

Received: November 24, 2017

Accepted: December 8, 2017 Online Published: December 21, 2017

doi:10.5430/ijfr.v9n1p132

URL: https://doi.org/10.5430/ijfr.v9n1p132

\begin{abstract}
The commercial banks (CBs) performance evaluating has been a necessary problem in currently integration trend and usually implemented by a committee of experts under criteria selected. Therefore, it is considered as a Multi Criteria Decision - Making model (MCDM). Nowadays, there have been many researches proposing various standards and models to evaluate and rank CBs. But in Vietnam, the number of studies related to the Vietnamese banking evaluation model have still been limited. As a result, this study develops a multi-criteria decision model integrating Fuzzy Analytical Hierarchy Process (FAHP) and Fuzzy the Technique for Order of Preference by Similarity to Ideal Solution (FTOPSIS). The proposed model has evaluated and ranked five Vietnamese commercial banks including CTG, VCB, BIDV, TCB and MB. The paper revealed their ranks. Besides, the results of the research show that the Analytical Hierarchy Process (AHP) model is suitable for applying it to the process evaluating bank performance.
\end{abstract}

Keywords: bank performance, evaluation criteria, MCDM, FAHP, FTOPSIS

\section{Introduction}

In most countries, commercial bank is one of the most important financial institutions. It can attract financial flows, offer offering credit and various financial services. These activities have a vital impact on national economic development. Therefore, CBs should be evaluated and analyzed by the modern and accurate techniques to rank CBs in the banking system and improve their performances.

Vietnam has still on the way international integration, which brings both opportunities and challenges for the economy, especially the banking system. Economic integration brings a healthily and equally competitive environment to CBs. Moreover, it brings exchange opportunities and international cooperation in fiscal and monetary policy planning, foreign exchange management, risk inspection and monitoring. Therefore, the position and prestige of Vietnamese CBs in the global transaction banking will be enhanced. Besides these opportunities, the banking system has to face competition from international banks in terms of price, service, distribution... Meanwhile, Vietnamese CBs are highly unlikely to assert their position in international markets because of their weak competitive abilities (Pham, 2010)

There aren't any banks which can fully satisfy all customers' requirements obviously. If a bank has an advantage in this respect, it will have disadvantages in other respects. Therefore, in the open market with the participation of more domestic and international banks, Vietnamese CBs must promote their strengths and improve their weaknesses in order to maintain and increase market share as well as profits. It creates a need to reassess Vietnamese CBs performance by the most accurate and modern techniques in order to satisfy many different objects.

Optimal selection process is related to evaluating many different options which based on a set of standards. This process is considered as Multi-criteria Decision Making (MCDM). Professor Zadeh (1965) researched on fuzzy set theory to solve blurring and unclear problem. Fuzzy decision-making makes approximate decision instead of absolute one. Fuzzy MCDM is one of the most important fields in the analysis of making decisions. As mentioned above, the decision-making depends on a lot of standards. The proportion of each decision correspond with criteria, the importance weighs of different criteria are evaluated by linguistic value and presented by fuzzy numbers. This 
study develops a multi-criteria decision making model integrating AHP and TOPSIS under a set of criteria to evaluate and rank CBs in Vietnam.

This paper is organized as follow. In section 2, we overview previous researches to propose a model and criteria. In section 3, we define data and methodology to evaluate banks. In section 4, we illustrate empirical results. In section 5, we discuss about the results. Anh in the last section, we conclude the paper by reviewing our research.

\section{Literature Review}

Performance is how economic resources should be used to achieve the objective of the business (N. Venkatraman and Ramanujam V., 1986). It is a complicated definition, should be analyzed under different ways. It is considered as an important factor when researching the business policy of the enterprise (Dess and Robinson, 1984). Ngo and Le (2008) pointed out that performance is a general economic indicator. It shows the possibility of using human, financial and material resources in order to maximize profit for business. Performance is evaluated based on the results that the business can achieve in a certain period of time and this result is the difference between the degree of completion and target (Cetindere, Duran \& Yetisen, 2015).

From those points of view, it can be seen that the definition of performance is various. It can be defined in many different ways depending on the purpose of the research. The definition of performance used in this study is an economic category showing the relationship between benefit and cost, it reflects the ability of an enterprise appropriately using and allocating inputs in order to produce outputs.

The majority of economists and analysts use ROA and ROE to approach performance (citation). They are the important indicators for evaluating bank performance. However, using only 2 indicators had certain shortcomings (Avkiran (1997) Lindblom \& Koch (2002) Chapman et al. (2007). Many researchers have developed some financial indicators to assess fully and accurately the performance of CBs. The studies used the model of Schierenbeck's ROE Scheme (also called basic ROE model) (Badreldin (2009); Tamosaitiene (2011)). These models are based on the Dupont analysis, divided ROE into three distinct elements: net profit margin, risk margin and equity multiplier. The model used in the study by Collier and McGowan (2010) broke down ROE into net profit margin, asset turnover and equity multiplier.

In 2010, European Central Bank introduced a financial index combining three categories: traditional category, economic category and market category. Nguyen (2012) used Financial Soundness Indicators (FSIs) to evaluate charted capital, asset quality, performance and liquidity of CBs in Vietnam.

Realizing that the simple description of financial situation through financial ratios was not sufficient to assess performance in today's volatile environment (T. Chen and C. Chen, 2008), many researchers have used non-financial indicators to assess the bank's performance.

Abdelgawad and Fayek (2010) mentioned 8 factors affecting bank performance: profitability, productivity, human resources management, risk management, sales effectiveness, service quality, capital management and competitive position. Barros and Wanke (2016) found 3 important factors in bank performance: labor cost, capital cost and market shares. In another study, Barros and Wanke (2015) pointed out that Malaysia financial market applying the rules of cultural barriers to foreign banks led to lower bank performance.

The studies of Wirnkar and Tanko (2008), Phan (2013) analyzed financial performance of the banking system through 5 key aspects of bank's activities: capital adequacy, asset quality, management quality, earnings ability and liquidity. J.Stankeviciene and Mencaite E (2012) pointed out that financial aspect was the most important one affecting bank performance. Besides, customer aspect also contributed to performance of the banking system significantly.

There are various research methodologies used to evaluate and rank CBs, such as Balanced Scorecard (BSC), Multi-criteria decision making (MCDM), Artificial intelligence (AI), Data Envelopment Analysis (DEA), Integrating Linear Programming. Meanwhile, Multi-criteria decision making mainly includes: Analytic hierarchy process (AHP), Analytic network process (ANP), Technique for Order of Preference by Similarity to Ideal Solution (TOPSIS).The banking performance evaluation is complicated with linguistic judgments under each criterion, this study develops a multi-criteria decision making model integrating AHP and TOPSIS under a set of criteria to evaluate and rank CBs in Vietnam. Meanwhile, TOPSIS and AHP have been the optimal methods to handle and rank fuzzy numbers so far.

\section{Methodology and Data Description}

In this section, we define data and methodology to evaluate bank. We start with the concepts of fuzzy set which will help us after then. There are many different concepts of fuzzy set. This study defines it as follows (Dubois and Prade, 
1978; Kaufmann and Gupta, 1991). Basing on database from both the financial reports of 05 banks and knowledge about them, we make committee of 3 decision makers (experts) to assess them. Then expert members will hold responsible for evaluating $\mathrm{CBs}$ with respect to criteria selected.

\subsection{Fuzzy Sets}

As fuzzy set will intervene in our evaluation model, we first present it here.

Fuzzy set A in a universe $\mathrm{U}$ is expressed as:

$$
A=\left\{x, f_{A}(x) / x \in U\right\}
$$

Set $\mathrm{A}$ is characterized by a membership function $f_{A}(x)$ which associates with each element $\mathrm{x}$ in $\mathrm{U}$ a real number in the interval $[0,1]$. The function value $f_{A}(x)$ is termed the grade of membership of $\mathrm{x}$ in A (Kaufmann and Gupta, 1991). The larger the function value of $f_{A}(x)$ is, the stronger the degree of membership for $\mathrm{x}$ in $\mathrm{A}$ will be.

\subsubsection{Triangular Fuzzy Numbers}

The triangular fuzzy numbers are used in this study because they are simply calculated and widely applied in studies relating to economics and governance. Characteristics and natures of the triangular fuzzy numbers are expressed as follows:

A normalized triangular fuzzy number A can be defined as A ( $a, b, c, 1)$. The membership function $\mathrm{f}_{\mathrm{A}}(\mathrm{x})$ of $\mathrm{A}$ in expressed as (Kaufmann and Gupta, 1991).

$$
f_{A}(x)=\left\{\begin{array}{c}
f_{A}{ }^{L}(x), a \leq x \leq b \\
1, \mathrm{~b} \leq \mathrm{x} \leq \mathrm{c} \\
f_{A}{ }^{R}(x), \mathrm{c} \leq x \leq d \\
0, \text { otherwise }
\end{array}\right.
$$

Figure 1. Triangular fuzzy number A

Where $f_{A}^{L}(x), f_{A}^{R}(x)$ are the left and right membership functions of fuzzy number A, respectively, especially if $\mathrm{a}=\mathrm{b}=\mathrm{c}$, fuzzy number $\mathrm{A}$ is a real number.

Let $A$ and $B$ be triangular fuzzy numbers, namely $A=\left(a_{1}, a_{2}, a_{3}\right)$ and $B=\left(b_{1}, b_{2}, b_{3}\right)$, some operations between A and B can be expressed as follows:

$$
\begin{gathered}
A+B=\left(a_{1}+b_{1}, a_{2}+b_{2}, a_{3}+b_{3}\right) \\
A-B=\left(a_{1}-b_{3}, a_{2}-b_{2}, a_{3}-b_{1}\right) \\
A \times B=\left(a_{1} b_{1}, a_{2} b_{2}, a_{3} b_{3}\right) \\
A / B=\left(a_{1} / b_{3}, a_{2} / b_{2}, a_{3} / b_{1}\right) \\
A \times k=\left(a_{1} k, a_{2} k, a_{3} k\right), \text { For } x \in U \\
\left(a_{1}, a_{2}, a_{3}\right)^{-1} \approx\left(1 / a_{3}, 1 / a_{2}, 1 / a_{1}\right)
\end{gathered}
$$

\subsubsection{Linguistic Values}

Linguistic variable is a useful concept to solve some solutions which are complex and cannot be expressed apparently in a traditional quantitative form. Linguistic values are those values represented in words or sentences in 
natural or artificial languages..Linguistic variables are used by decision makers to assess the weights of the criteria and the ratings of the alternatives. Then they are specified by triangular fuzzy numbers. In this paper, the ratings and weights of the alternatives are denoted in linguistic values and listed in table 1.

Table 1 . The triangular fuzzy numbers of linguistic variables

\begin{tabular}{llll}
\hline & Linguistic variables & Triangular fuzzy numbers & Reciprocal triangular fuzzy scale \\
\hline$(1)$ & Unimportant & $(1,1,3)$ & $(1 / 3,1,1)$ \\
\hline$(2)$ & Slightly important & $(1,3,5)$ & $(1 / 5,1 / 3,1)$ \\
\hline$(3)$ & Moderately important & $(3,5,7)$ & $(1 / 7,1 / 5,1 / 3)$ \\
\hline$(4)$ & Seriously important & $(5,7,9)$ & $(1 / 9,1 / 7,1 / 5)$ \\
\hline$(5)$ & Very seriously important & $(7,9,9)$ & $(1 / 9,1 / 9,1 / 7)$ \\
\hline
\end{tabular}

\subsection{Multi-Criteria Decision-Making Model to Evaluate and Rank CBs}

As mentioned above, this paper uses the fuzzy sets indicating the weights of the criteria and the ratings of the alternatives in evaluation model applied to case study in section 4 after.

Based on the criteria selected to evaluate CBs, this study developed a fuzzy multiple criteria decision - making model integrating fuzzy AHP and fuzzy TOPSIS to assess and rank CBs. First, the fuzzy AHP method is used to determine the weights of the criteria based on the comparatively linguistic evaluatings of the decision makers. After having the ratings of the alternatives to each criterion, this paper aggregates them for the final fuzzy results of the alternatives. Then the fuzzy TOPSIS are used to handle them and give the final results for the evaluation to CBs. It is expressed as follows:

\subsubsection{Importance Weighs of Each Criterion}

This study defines the importance weighs of each criterion by fuzzy AHP approach of Chang's (1996) (pairwise comparisons).

a) Value of fuzzy synthetic extent

Let $X=\left\{x_{1}, x_{2}, \ldots x_{n}\right\}$ be an object set and $U=\left\{u_{1}, u_{2}, \ldots u_{m}\right\}$ be a goal set. According to the method proposed by Chang (1996), this paper analyses the extent. Therefore, we can get m extent analysis values for each object, with the following signs:

$$
M_{g_{i}}^{1}, M_{g_{i}}^{2}, \ldots, \mathrm{M}_{g_{i}}^{m} \quad \mathrm{i}=1,2, \ldots, \mathrm{n}
$$

Where all the $M_{g_{i}}^{j}(j=1,2, \ldots, m)$ are triangular fuzzy number

Then the value of fuzzy synthetic extent with respect to the i-th object is defined as:

$$
S_{i}=\sum_{j=1}^{m} M_{g_{i}}^{j} \square\left[\sum_{i=1}^{n} \sum_{j=1}^{m} M_{g_{i}}^{j}\right]^{-1}
$$

b) Fuzzy numbers for the pairwise comparison scale

By using triangular fuzzy numbers, via pairwise comparison, the fuzzy evaluation matrix $A=\left(a_{\mathrm{ij}}\right)_{n x m}$ is constructed. For instance, strong importance of element $i$ over element $j$ under a certain criterion is represented by $a_{i j}$ 
$=(1, \mathrm{~m}, \mathrm{u})$. On which strong importance of element $\mathrm{j}$ over element $\mathrm{i}$ can be represented by the fuzzy number $a_{\mathrm{ij}}^{-1}=(1 / u, 1 / m, 1 / l)$

c) Calculation of priority vectors of the fuzzy AHP

Let $A=\left(a_{\mathrm{ij}}\right)_{n x m}$ be a fuzzy pairwise comparison matrix, where $\mathrm{a}_{\mathrm{ij}}=\left(l_{\mathrm{ij}}, m_{\mathrm{ij}}, u_{\mathrm{ij}}\right)$, which are satisfied with

$$
l_{\mathrm{ij}}=\frac{1}{l_{j i}}, m_{\mathrm{ij}}=\frac{1}{m_{j i}}, u_{\mathrm{ij}}=\frac{1}{u_{j i}} .
$$

To obtain the estimates for the vectors of weights under each criterion, Chang compared in pairs among fuzzy numbers. In fact, question is which fuzzy number is the greatest among different fuzzy numbers. To resolve it, Chang evaluated the degree of possibility for $\mathrm{x} \in \mathrm{R}$ fuzzily restricted to belong to $\mathrm{M}$. He gave the definition as follows:

The degree of possibility of $M_{1} \geq M_{2}$ is defined as

$V\left(M_{1} \geq M_{2}\right)=\sup \left[\min \left(f_{M_{1}}(x), f_{M_{2}}(\mathrm{y})\right)\right]$

Where a pair (x, y) exists that $\mathrm{x}>=\mathrm{y}$ and $f_{M_{1}}(x)=f_{M_{2}}(y)=1$, then we have $V\left(M_{1} \geq M_{2}\right)=1$. Because $\mathrm{M}_{1}$ and $\mathrm{M}_{2}$ are convex fuzzy numbers, we have that:

$V\left(M_{1} \geq M_{2}\right)=1$ Iff $m_{1} \geq m_{2}$

$V\left(M_{2} \geq M_{1}\right)=\operatorname{hgt}\left(\mathrm{M}_{1} \cap M_{2}\right)=f_{M_{1}}(d)$

Where $\mathrm{d}$ is the ordinate of the highest intersection point $\mathrm{D}$ between $f_{M_{1}}$ and $f_{M_{2}}$

When $\mathrm{M}_{1}=\left(\mathrm{l}_{1}, \mathrm{~m}_{1}, \mathrm{u}_{1}\right)$ and $\mathrm{M}_{2}=\left(\mathrm{l}_{2}, \mathrm{~m}_{2}, \mathrm{u}_{2}\right)$, the ordinate of $\mathrm{D}$ is calculated by the following equation:

$$
V\left(M_{2} \geq M_{1}\right)=\operatorname{hgt}\left(\mathrm{M}_{1} \cap M_{2}\right)=\frac{l_{1}-u_{2}}{\left(m_{2}-u_{2}\right)-\left(m_{1}-l_{1}\right)}
$$

To compare $\mathrm{M}_{1}$ and $\mathrm{M}_{2}$, we need both the values of $V\left(M_{1} \geq M_{2}\right)$ and $V\left(M_{2} \geq M_{1}\right)$

The degree possibility for a convex fuzzy number to be greater than $k$ convex fuzzy numbers $M_{i}(i=1,2 \ldots k)$ can be defined by

$$
\begin{aligned}
& V\left(M \geq M_{1}, \mathrm{M}_{2}, \ldots, \mathrm{M}_{k}\right) \\
& =V\left[\left(M \geq M_{1}\right) \text { and }\left(M \geq M_{2}\right) \text { and ...and }\left(M \geq M_{k}\right)\right] \\
& =\min V\left(M \geq M_{i}\right) \quad \mathrm{i}=1,2 \ldots \mathrm{k}
\end{aligned}
$$

Assume that $\mathrm{d}^{\prime}\left(A_{i}\right)=\operatorname{minV}\left(\mathrm{S}_{i} \geq S_{k}\right)$

for $\mathrm{k}=1,2, \ldots, \mathrm{n} ; \mathrm{k} \# \mathrm{i}$. Then the weight vector is given by:

$$
\mathrm{W}^{\prime}=\left(d^{\prime}\left(A_{1}\right), d^{\prime}\left(A_{2}\right), \ldots, d^{\prime}\left(A_{n}\right)\right)^{T}
$$

Where $A_{i}(i=1,2 \ldots n)$ are $n$ elements

Via normalization, we get the normalized weight vectors as follows: 
$\mathrm{W}=\left(d\left(A_{1}\right), d\left(A_{2}\right), \ldots, d\left(A_{n}\right)\right)^{T}$, where $\mathrm{W}$ is a nonfuzzy number, $d\left(A_{1}\right), d\left(A_{2}\right), \ldots, d\left(A_{n}\right)$ are weights of $\mathrm{n}$ elements $\mathrm{w}=\left(\mathrm{w}_{1}, \mathrm{w}_{2} \ldots \mathrm{w}_{3}\right)$

\subsubsection{Averaged Ratings of Alternatives under Each Criterion}

Let $x_{i j t}=\left(\mathrm{m}_{i j t}, \mathrm{n}_{i j t}, \mathrm{p}_{i j t}\right), i=1, \ldots, m, j=1, \ldots, \mathrm{n}, t=1, \ldots, k$, be the suitable rating assigned to alternative $A_{i}$, by decision maker $D_{t}$ versus each criterion $C_{j}$. The averaged rating of alternative $A_{i}$ under criterion $C_{j}$ evaluated by committee of $\mathrm{k}$ decision makers can be expressed as follows:

$$
x_{i j}=\frac{1}{k} \otimes\left(x_{i j 1} \oplus x_{i j 2} \oplus \ldots \oplus x_{i j t} \oplus \ldots \oplus x_{i j k}\right)
$$

In which,

$$
m_{i j}=\frac{1}{k} \sum_{t=1}^{k} e_{i j t}, \mathrm{n}_{i j}=\frac{1}{k} \sum_{t=1}^{k} f_{i j t}, \mathrm{p}_{i j}=\frac{1}{k} \sum_{t=1}^{k} g_{i j t}
$$

Linguistic values and corresponding fuzzy numbers for each alternative are expressed in table 1

\subsubsection{Normalize Performance of Alternatives versus each Criterion}

The evaluation criteria are divided into Benefit (B) and Cost (C) criteria. The greater benefit criteria are, the better they are. The smaller cost criteria are, the better they are. To ensure compatibility between average ratings and average weighs, they need be normalizeded in comparable interval. Suppose that $y_{i j}=\left(\mathrm{o}_{i j}, \mathrm{p}_{i j}, \mathrm{q}_{i j}\right)$ is the average rating of alternative $\mathrm{i}$ under criterion $\mathrm{j}$, the normalized rating $x_{\mathrm{ij}}$ can be calculated as follows:

$$
\begin{aligned}
& x_{i j}=\left(\frac{o_{i j}}{q_{j}^{*}}, \frac{p_{i j}}{q_{j}^{*}}, \frac{q_{i j}}{q_{j}^{*}}\right), j \in B \\
& x_{i j}=\left(\frac{o_{j}^{-}}{q_{i j}}, \frac{o_{j}^{-}}{p_{i j}}, \frac{o_{j}^{-}}{o_{i j}}\right), j \in C
\end{aligned}
$$

Where $o_{j}^{-}=\min _{i} o_{i j}, \mathrm{q}_{j}^{*}=\max _{i} q_{i j}, i=1, \ldots, m ; j=1, \ldots, n$.

\subsubsection{The Final Evaluating Value versus Each Alternative}

That the membership function of $T_{i}, \mathrm{i}=1,2, \ldots, \mathrm{m} ; \mathrm{j}=1,2, \ldots, \mathrm{n}$ corresponds with $\mathrm{n}$ objects to rank and select is final values versus each alternative. They can be denoted as follows:

$$
T_{i}=\sum_{j=1}^{n}\left(x_{i j} \otimes w_{j}\right)
$$

TOPSIS approach was applied to defuzzyficate $\mathrm{T}_{\mathrm{i}}$

\section{The fuzzy TOPSIS approach}


The fuzzy TOPSIS approach was proposed by Chen (2000) to solve the multiple criteria making problems under the uncertain criteria.

(1) With the final value $\mathrm{T}_{\mathrm{i}}$, the fuzzy positive ideal solution (FPIS A ${ }^{+}$) and the fuzzy negative ideal solution (FNIS A-) are expressed as follows:

$$
\begin{aligned}
& A^{+}=\left\{v_{1}^{+}, v_{j}^{+}, \ldots, v_{m}^{+}\right\} \\
& A^{-}=\left\{v_{1}^{-}, v_{j}^{-}, \ldots, v_{m}^{-}\right\}
\end{aligned}
$$

Where, $v_{j}^{+}=(1,1,1)$ and $v_{j}^{-}=(0,0,0)$

(2) Compute the distances $\mathrm{d}^{+}$and $\mathrm{d}^{-}$of each alternative from respectively $v_{j}^{+}$and $v_{j}^{-}$according to the following equations:

$$
\begin{aligned}
& d_{i}^{+}=\sum_{j=1}^{n} d_{v}\left(v_{\mathrm{ij}}, v_{j}^{+}\right) \\
& d_{i}^{-}=\sum_{j=1}^{n} d_{v}\left(v_{\mathrm{ij}}, v_{j}^{-}\right)
\end{aligned}
$$

where $\mathrm{d}(\ldots)$ represents the distance between two fuzzy numbers according to the vertex method. For triangular fuzzy numbers, this is expressed as in Eq. (11)

$$
\mathrm{d}(\mathrm{x}, \mathrm{z})=\sqrt{\frac{1}{3}\left[\left(l_{x}-l_{z}\right)^{2}+\left(m_{x}-m_{z}\right)^{2}+\left(u_{x}-u_{z}\right)^{2}\right]}
$$

(3) Compute the closeness coefficient $\mathrm{CC}_{\mathrm{i}}$ according to Eq. (12)

$$
C C_{i}=\frac{d_{i}^{-}}{d_{i}^{+}+d_{i}^{-}}
$$

(4) Ranking the alternatives according to the closeness coefficient $\mathrm{CC}_{\mathrm{i}}$, the best alternative is the closest to the FPIS and the farest to the FNIS.

\section{Results}

In this study, to demonstrate the model's applicability and effectiveness, the proposed model was applied to evaluate and rank five CBs in Vietnam's banking system (Vietinbank, Vietcombank, BIDV, MB and Techcombank). They are the top of five biggest banks in Vietnam. Because the banking system significantly impacts on the economic system, we need to evaluate thoroughly and carefully the banking system in order to ensure "financial health" of the economy.

\subsection{Importance Weighs of Each Criterion}

This study proposed 26 criteria based on previous studies to solve the decision-making problems of businesses especially CBs. Furthermore, this study proposed a criterion (ownership structure) to suit more with Vietnamese market. 
Table 2. Fuzzy weights of each criterion by fuzzy AHP

\begin{tabular}{|c|c|c|}
\hline Criteria & Local & Overall \\
\hline (C1) Finance & 0.430856 & \\
\hline (SC11) Net income & 0.311921 & \\
\hline (SC111) Provisions for loans/ Net interest income & 0.149183 & 0.020049 \\
\hline (SC112) Loan loss reserves/Gross loans & 0.142688 & 0.019176 \\
\hline (SC113) Operating cost/Operating income & 0.144940 & 0.019479 \\
\hline (SC114) Operating income /The total number of employees & 0.132881 & 0.017858 \\
\hline (SC115) Profit before tax/Total equity & 0.138656 & 0.018634 \\
\hline (SC116) Profit before tax /Total assets & 0.146862 & 0.019737 \\
\hline (SC117) Profit before tax /Operating income & 0.144789 & 0.019459 \\
\hline (SC12) Liquidity & 0.080542 & \\
\hline (SC121) Quick ratio & 0.536713 & 0.018625 \\
\hline (SC122) Current ratio & 0.463287 & 0.016077 \\
\hline (SC13) Credit risk & 0.317114 & \\
\hline (SC131) Total equity/Gross loans & 0.157042 & 0.021457 \\
\hline (SC132) Total deposits/Total equity & 0.159295 & 0.021764 \\
\hline $\begin{array}{l}\text { (SC133) Cash and cash equivalent }+ \text { Cash due from financial } \\
\text { institutions/Total deposits }\end{array}$ & 0.170339 & 0.023273 \\
\hline (SC134) Gross loans/Total deposits & 0.176466 & 0.024111 \\
\hline (SC135) Non-performing loans/Gross loans & 0.157682 & 0.021544 \\
\hline (SC136) Capital adequacy ratio & 0.179176 & 0.024481 \\
\hline (SC14) Scale & 0.290424 & \\
\hline (SC141) Total assets & 0.603413 & 0.075506 \\
\hline (SC142) Total liabilities/Total equity & 0.396587 & 0.049625 \\
\hline (C2) Customer & 0.383849 & \\
\hline (SC21) Accessibility for customers & 0.309575 & 0.118830 \\
\hline (SC22) The evaluation of the Internet page & 0.383794 & 0.147319 \\
\hline (SC23) The number of new services and products & 0.306631 & 0.117700 \\
\hline (C3) Non-finance & 0.185295 & \\
\hline (SC31) Support from main shareholders & 0.155355 & 0.028786 \\
\hline (SC32) Bank management & 0.174299 & 0.032297 \\
\hline (SC33) Market share & 0.171973 & 0.031866 \\
\hline (SC34) Employee stability & 0.186333 & 0.034527 \\
\hline (SC35) Ownership structure & 0.143676 & 0.026622 \\
\hline (SC36) Differentiation & 0.168364 & 0.031197 \\
\hline
\end{tabular}

\subsection{Averaged Ratings of Alternatives under Each Criterion}

In this step, the panel of experts will evaluate each bank under selected criteria. After a preliminary assessment, five banks (A1, A2, A3, A4 and A5) are evaluated and ranked to choose the best bank. The average evaluating values of CBs under the criteria from the panel of three experts are calculated by using Eps. (5)-(8) and table 1.

\subsection{The Final Evaluating Value versus Each Alternative}

Finally, in order to get the final evaluating value for each alternative, this study integrates the importance weighs of each criterion and the averaged ratings of alternatives under each criterion. Then this study applies fuzzy TOPSIS 
method presented in chapter 2 and using Eqs. (9) - (12) to defuzzyficate the final values and rank alternatives.

Table 3. Ranking CBs by fuzzy TOPSIS

\begin{tabular}{lll}
\hline CBs & CCi & Rank \\
\hline Vietinbank & 0.475018 & 2 \\
Vietcombank & 0.494919 & 1 \\
BIDV & 0.471353 & 3 \\
MB & 0.452061 & 4 \\
Techcombank & 0.435054 & 5 \\
\hline
\end{tabular}

\section{Discussion}

This study evaluated 5 banks under 26 criteria, including both financial and non-financial criteria. To solve this problem, this study developed an integrated multi-criteria decision making AHP - TOPSIS to determine the weight of criteria and the evaluation rate for 5 banks under each criteria.

AHP method showed the fuzzy weight of criteria. The table (4.3) showed that the financial criteria is the most important one affecting the bank performance $(0.43)$, followed by customer perspective $(0.38)$ and qualitative criteria (0.18). Because banking industry is a special service sector, whose performance has close relationship with the customer's satisfaction. Therefore, in order to maintain high performance, the banking system must enhance financial indicators, maintain the loyalty and trust of customers and build new markets to attract new customers.

Besides, the fuzzy TOPSIS method determined the final value to rank 5 banks and show the standard satisfaction among 5 banks. The table (4.6) told us that the bank had the best performance (Vietcombank) is more dominant in financial indicators over other CBs. Moreover, qualitative criteria are good. Besides, Techcombank and MB are two banks having the worst performance among 5 proposed banks. We can explain that because these banks had worse financial performance than other banks, while financial criteria are the most important factors affecting bank performance.

\section{Conclusion}

This research showed the multi- criteria decision - making model to evaluate and rank CBs, comprising the steps of: (i) determining the evaluation criteria; (ii) determining the weighted average with criteria; (iii) determining the CBs' proportion of value by the panel of experts based on criteria; (iv) determining integration value of the CBs' weighted percentages; (v) evaluating and ranking CBs. Proposed model is applied to help the institutions evaluate and rank CBs in the system.

The use of fuzzy set theory through the use of linguistic variables helped to soften the decision-making process, especially in the case of evaluation criteria including both qualitative and quantitative criteria with unclear input information. The following research can be applied the proposed model to solve the problem for all banks in the system and compare the result obtained from the proposed model with different decision-making models.

\section{References}

Abdelgawad, M., \& Fayek, A. R. (2010). Risk Management in the Construction Industry Using Combined Fuzzy FMEA and Fuzzy AHP. Journal of Construction Engineering and Management, 136(9), 1028-1036. https://doi.org/10.1061/(ASCE)CO.1943-7862.0000210

Badreldin, A. M. (2009). Measuring the Performance of Islamic Banks by Adapting Conventional Ratios. Faculty of Management Technology, German University in Cairo. https://doi.org/10.2139/ssrn.1492192

Barros, C. P., \& Wanke, P. (2015). An analysis of African airlines efficiency with two-stage TOPSIS and neural networks. Journal of Air Transport Management, 44-45, 90-102. https://doi.org/10.1016/j.jairtraman.2015.03.002

Cetindere, A., Duran, C., \& Yetisen, M. S. (2015). The effects of total quality management on the business performance: An application in the province of Kütahya. Procedia Economics and Finance, 23, 1376-1382. https://doi.org/10.1016/S2212-5671(15)00366-4

Chang, D.-Y. (1996). Applications of the extent analysis method on fuzzy AHP. European Journal of Operational 
Research, 95(3), 649-655. https://doi.org/10.1016/0377-2217(95)00300-2

Chen, T., \& Chen, C. (2008). Firm operation performance analysis using data envelopment analysis and balanced scorecard: A case study of a credit cooperative bank. International Journal of Productivity and Performance Management, 57(7), 523-539. https://doi.org/10.1108/17410400810904010

Collier, H. W., Junior, C. B. M., \& Muhammad, J. (2010). Evaluating the impact of a rapidly changing economic environment on bank financial performance using the Dupont System of financial analysis. Asia Pacific Journal of Finance, 4(4), 25-35.

Dess, G. G., \& Robinson, R. B. J. (1984). Measuring Organizational Performance in the Absence of Objective Measures: Th... Strategic Management Journal, 5(3), 265-273. https://doi.org/10.1002/smj.4250050306

Dubois, D., \& Prade, H. (1979). Operations in a fuzzy-valued logic. Information and Control, 43(2), 224-240. https://doi.org/10.1016/S0019-9958(79)90730-7

European Central Bank. (2010). Beyond RoE - How to measure bank performance.

Kauffmann, A., \& Gupta, M., M. (1991). Introduction to Fuzzy Arithmetic.

Ngo, K.T., \& Le, V.T. (2008). Corporate Governance. National Economics University, Ha Noi.

Nguyen, T.M.H. (2012). Evaluating Vietnam's banking system through Financial Soundness Indicators. Scientific journal of Vietnam National University Ha Noi, Economics and Bussiness, 28, 158-166.

Pham, T.H. (2010). Vietnam's commercial banks in global integration, opportunities and threats. Journal of Auditing studies.

Phan, T.H.N (2013). Financial capability of Vietnam's commercial banks. Ph.D thesis. Banking University of Ho Chi Minh City.

Stankevičienè, J., \& Mencaite, E. (2012). The evaluation of bank performance using a multicriteria decision making model: a case study on Lithuanian CBs. Technological and Economic Development of Economy, 18(1), 189-205. https://doi.org/10.3846/20294913.2012.668373

Tamošaitienė, J., Zavadskas, E. K., Turskis, Z., \& Vainiūnas, P. (2011). Multi-criteria complex for construction profitability analysis of construction projects. Economics \& Management, 16, 969-973.

Venkatraman N., \& Ramanujam Vasudevan. (1986). Measurement of Business Performance in Strategy Research: A Comparison of Approaches. The Academy of Management Review, 11(4), 801-814.

Wanke, P., Barros, C. P., \& Emrouznejad, A. (2016). Assessing productive efficiency of banks using integrated Fuzzy-DEA and bootstrapping: A case of Mozambican banks. European Journal of Operational Research, 249(1), 378-389. https://doi.org/10.1016/j.ejor.2015.10.018

Wirnkar, A., \& Tanko, M. (2008). CAMELS and banks performance evaluation: The way forward. Retrieved May, $1-21$. 